\title{
Ultrasound in the diagnosis and measurement of aneurysms of the abdominal aorta
}

\author{
DAVID SUTTON \\ M.D., F.R.C.P., F.R.C.R.
}

\author{
R. G. GARNER* \\ F.R.C.R.
}

Radiological Department, St Mary's Hospital, London W2

\begin{abstract}
Summary
One hundred cases clinically diagnosed as aneurysm of the abdominal aorta were examined by ultrasound. The findings are described and the value and limitations of the method assessed.

IN the last decade ultrasound by the $B$ scan or imaging technique has been increasingly used in medical diagnosis. In this country the method has been most widely used in obstetric work, although individual workers have also used this method for imaging renal, hepatic and other abdominal lesions.

Several American authors have reported encouragingly on the use of sonar in the diagnosis and assessment of small series of abdominal aneurysms. However the method does not seem to be widely used in this country and as yet no large British series has been reported. Since February 1971 the authors have assessed by ultrasound all patients referred to the X-ray department, St Mary's Hospital, with a diagnosis of aortic aneurysm. The first 100 suspected cases were reviewed.
\end{abstract}

\section{Method}

A Kretz 4100 MG ultrasound was used in the majority of cases. The most suitable probe was found to be a two- $\mathrm{MHz}$ crystal transducer, although in very obese patients a one-MHz transducer was needed. This gives a slightly poorer resolution. Acoustic coupiing was accomplished by painting the skin with arachis oil. More recently the authors have used a Nuclear Enterprise Diasonograph employing an identical technique.

Ultrasound examinations depend on the production of echoes at interfaces where tissue densities and therefore acoustic impedances change. Therefore in an aorta containing fluid blood only, the lumen will be echo-free. Should clot be present, however, this may show numerous echoes as the gain is increased. The increase in gain must be carried out carefully, as too great an increase will lead to excessive echo formation which will render the A scan unreadable, and then obliterate the B scan.

Results are obtained in two ways. Firstly, on the B scan which produces a two-dimensional section in
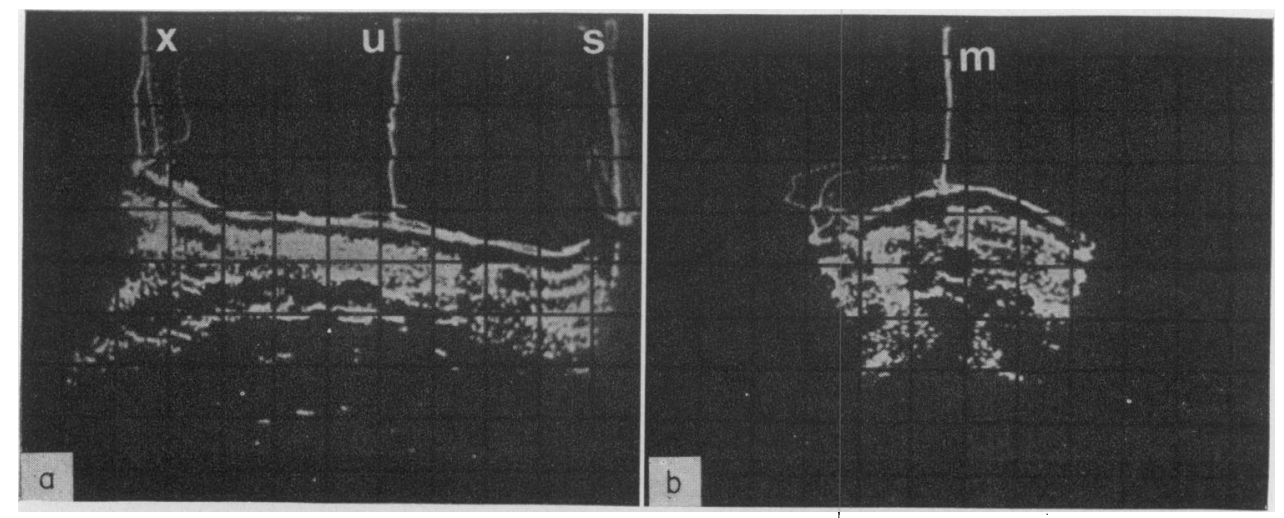

FIG. 1. Normal aorta in (a) longitudinal section; (b) transverse section. The diameter was not above $2 \mathrm{~cm}$. $\mathrm{m}=$ midline line; $\mathrm{u}=$ umbilicus; $\mathrm{s}=$ symphysis; $\mathrm{x}=$ xiphisternum.

* Now at Shotley Bridge Hospital, Durham. 
the line of the probe movement, and is recorded on Polaroid film, and secondly on the A scan, where the echoes are recorded as a series of waves. From the A scan measurements are obtained using an electronic cursor. Measurements were carried out in the antero-posterior and transverse planes as far as possible. Transverse measurements of the upper abdominal aorta are not possible, as overlying aircontaining lung effectively blocks ultrasound signals.

Criteria for the diagnosis of abdominal swellings by ultrasound were discussed by Freimanis and Asher (1970). Papers by Goldberg and Lehman (1970) and by Nusbaum, Freimanis and Asher (1971) discuss the diagnosis of aortic aneurysms. The latter suggest the diagnosis is confirmed:

(a) if there is a sudden increase in aortic diameter compared with measurements obtained above and below;

(b) in a fusiform dilatation if the diameter exceeds $3 \mathrm{~cm}$ at any point.

\section{Discussion}

The authors have found sonar to be a very satisfactory method of confirming or excluding the presence of an aortic abdominal aneurysm and in some cases of suggesting an alternative diagnosis. They have long been aware that a small proportion of patients who are diagnosed clinically as having aortic aneurysm will have normal aortas. This mistake is most commonly made in very thin patients where the aorta may be strongly pulsatile and almost subcutaneous. The error can be made even by experienced clinicians. With increasing experience they have found that the demonstration of the external dimensions of the aneurysms and of the presence or absence of clot could be carried out reasonably quickly. Troublesome interference is sometimes encountered, particularly in obese patients, from $\varnothing$ gassy distension of the bowel. This causes difficulty $\measuredangle$ in obtaining a precise diameter although it could $\overrightarrow{\vec{c}}$ sometimes be overcome by applying varied pressure $\frac{?}{\sigma}$ to displace the bowel. Figures 2 and 3 show typical $\frac{}{2}$ appearances of aneurysms at sonar. Variations from $\frac{\bar{\sigma}}{\bar{\omega}}$ the commonly encountered fusiform aneurysms can $\frac{\vec{\Phi}}{\widehat{D}}$ be shown. For example, gross kinking in the anterior $\varrho$ or lateral plane can be identified (Fig. 2).

A major limitation of the method is the impossi- $\overrightarrow{0}$ bility of defining and relating the upper end of the lesion to the renal arteries, information once regarded $\vec{\omega}$ as vital in planning surgery. Perforce, one has to $\frac{\rho}{\circ}$ assume a normal anatomical level for these vessels. $\frac{0}{7}$ A few aneurysms will obviously extend above it and a 3 . few will be clearly below it but the majority will of extend into this region and it is not usually possible o to define their upper limit. Again no indication of the $O$ condition or patency of the main visceral vessels can $\stackrel{\nexists}{\not}$ be obtained as at aortography, nor in the authors' $\vec{D}$ experience can the iliac vessels be readily identified. $\frac{\text { ? }}{2}$ The latter are not infrequently involved in aortic $\vec{\nabla}$ aneurysms.

The modern method of treatment of aortic $\underset{\mathbb{\Phi}}{\mathbb{Q}}$ aneurysms is with replacement by a dacron graft $\frac{3}{8}$ with the original aneurysm left in situ and by-passed. Postoperative sonar has been performed on many of $\overrightarrow{0}$ these cases and it is usually possible to identify the graft and show its relationship to the originas. aneurysm (Figs 4 and 5). However, if a graft det velops thrombosis or the occasional complication of aneurysm formation at the junction with aorta the authors have found that sonar is not very successful in showing the complication, and aortography will $\stackrel{\unrhd}{\unrhd}$ usually be necessary.

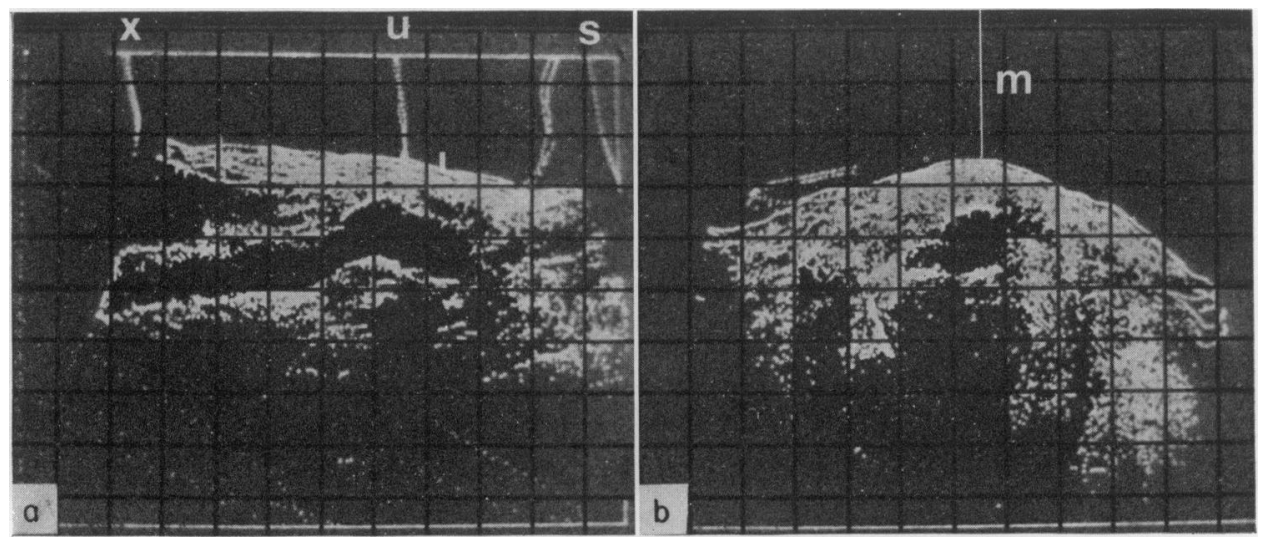

FIG. 2. (a) Longitudinal section of the aorta showing fusiform dilatation and kinking in the sagittal plane. Maximum sagittal diameter was $4.5 \mathrm{~cm}$. (b) Transverse section of same aneurysm at the level of the umbilicus. $\mathrm{m}=$ midline line; $\mathrm{u}=$ umbilicus; $\mathrm{s}=$ symphysis; $\mathrm{x}=$ xiphisternum. 


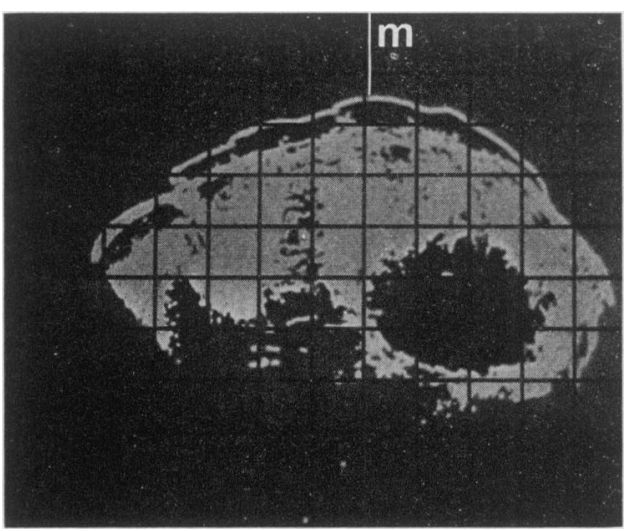

FIg. 3. Transverse section of a large aneurysm. Maximum transverse diameter was $7 \mathrm{~cm}$ and the aneurysm was kinked to the left of the mid-line (m).

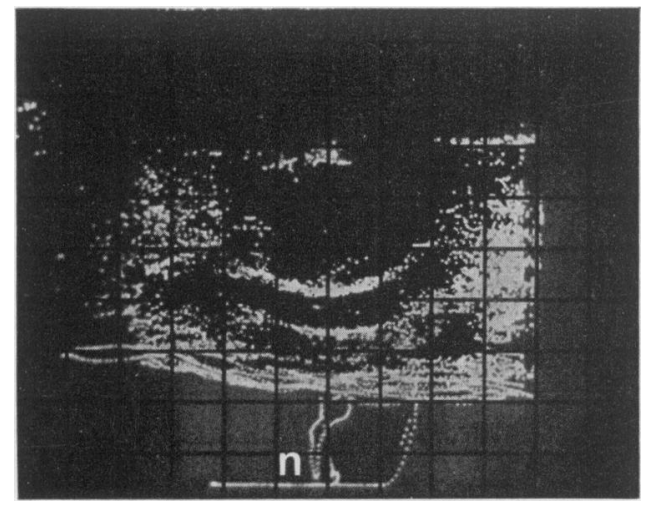

FIG. 4. Longitudinal section of abdominal aneurysm showing dacron graft lying over it and by-passing it. $\mathbf{u}=$ umbilicus.

\section{Findings}

Ultrasonic examination confirmed that 91 of 100 cases had abdominal aneurysm but showed that five cases clinically diagnosed as aneurysms had normal sized aortas (Fig. 1). Of the remaining four cases, two showed appearances suggestive of pancreatic cysts. One of these cases has been confirmed at surgery. Incidentally, this patient had a laparotomy in another country and was told that he had an aortic aneurysm! The second case thought to have a pancreatic cyst has not so far come to surgery. Of the remaining cases, one considered to be nonaneurysmal by sonar was operated on and the palpable mass was shown to be due to para-aortic glands affected by follicular lymphoma. In the final

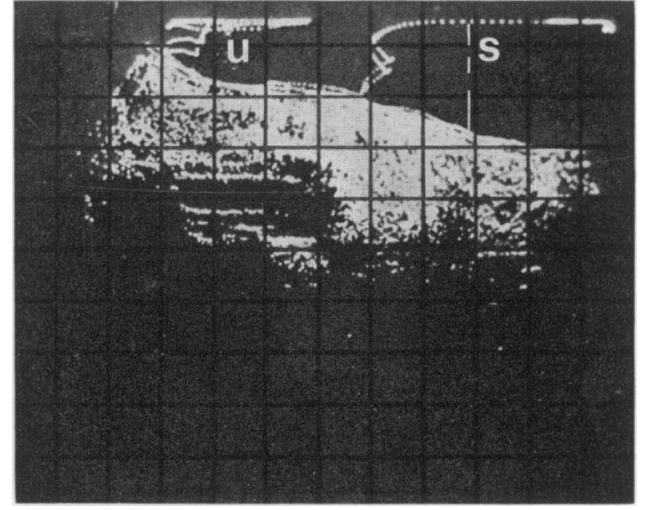

Fig. 5. Longitudinal section of abdominal aneurysm showing postoperative dacron graft lying within the aneurysm. $\mathrm{u}=$ umbilicus; $\mathrm{s}=$ symphysis.

case it was not possible to obtain a satisfactory examination because of the patient's gross obesity and gas-distended bowel.

In thirty-five of the cases where a diagnosis of abdominal aneurysm was made by ultrasound the maximum diameters as measured were checked at operation (fifteen cases) or by angiography (thirty cases). In ten cases it was checked by both methods.

Patients who underwent aortography had the measurements of the aortic lumen corrected usually by a factor of 0.75 to allow for the photographic enlargement so produced. The correction figure was obtained by measuring the distance from cassette to anterior surface of the dependent lumbar vertebra as shown on a lateral film. This was then related to the anode film distance used for aortography. Measurements at operation were obtained by calipers directly on the aorta. In all cases except one there was a close correlation between the dimensions as measured by the different methods. In one early case there was a discrepancy and the aneurysm was found to be $11 \mathrm{~cm}$ in maximum diameter instead of $5 \mathrm{~cm}$ as suggested by the ultrasound. This isolated discrepancy was thought to be due to a fault in technique.

\section{Conclusion}

Sonar represents a simple non-traumatic method of confirming a diagnosis of abdominal aortic aneurysm avoiding the discomforts of aortography. It is a method very suitable for follow-up studies in patients not yet considered suitable for surgery. However, its limitations may need to be supplemented by angiography in specific cases where surgery is proposed or post-surgical complications have developed. 


\section{Acknowledgments}

We would like to thank Mr H. H. G. Eastcott, Mr J. R. Kenyon and $\mathrm{Mr}$ Crawford Jamieson under whose care most of these patients were admitted. Most of the operative measurements were obtained by the late Mr Barrie Thomas.

\section{References}

Freimanis, A. \& Asher, W.M. (1970) Development of diagnostic criteria in echographic study of abdominal lesions. American Journal of Roentgenology, 108, 747.

Goldberg, B. \& Lehman, J. (1970) Aortosonography: ultrasonic measurement of the abdominal and thoracic aorta. Archives of Surgery, 100, 652.

Nusbaum, J.W., Freimanis, A.K. \& Thomford, N.R. (1971) Echography in the diagnosis of abdominal aortic aneurysms. Archives of Surgery, 102, 385. 


\section{CORRIGENDUM}

\section{December 1977.}

In the article 'Ultrasound in the diagnosis and measurement of aneurysms of the abdominal aorta' by Sutton and Garner. The initials of the second author are E. B. not R. G. as printed.

\section{Subject Index \\ * denotes Case Report}

Abdominal aorta

aneurysms, ultrasonic measurements. December, 737, 741

* spontaneous rupture. April, 231

*Abortion, septic, due to invasive Salmonella agona. March, 155

*Acidosis, lactic, reversible, associated with repeated intravenous infusions of sorbitol and ethanol. September, 567

Acrylamide poisoning. January, 16

* Acupuncture associated with staphylococcal septicaemia with disseminated intravascular coagulation. May, 285

Advertisements and representatives as sources of information. September, 559

*Agnogenic myeloid metaplasia, disorder simulating in association with lung carcinoma. November, 702

Aluminium hydroxide and sodium bicarbonate, different effects on absorption of indomethacin. March, 126

*Ampicillin therapy associated with pseudomembranous enterocolitis. June, 324

Aneurysms, aortic

abdominal, ultrasonic measurements. December, 737, 741 coagulopathy associated with. November, 668

Angina pectoris, verapamil and practolol treatment, double-blind comparison. February, 61

*Angiokeratoma corporis diffusum: evolution of disease entity. February, 78

*Angiolipomata, multiple, and myocardial infarction, associated with diffuse intravascular coagulation. April, 228

*Angio-oedema, hereditary, with mesangiocapillary glomerulonephritis. October, 627

Anorexia nervosa

dental characteristics and dietary habits. June, 298

* with development of chlorpromazine-induced haemolytic anaemia. May, 278

primary (weight phobia) in males. March, 146

Antibacterial therapy in general medical wards. June, 306

Antibiotics

prophylaxis, perioperative, and prosthetic valve endocarditis. July, 353

review of erythromycin. April, 195

*Antidiuretic hormone secretion, inappropriate associated with acute myocardial infarction. December, 761

* associated with carcinoma of the bladder. May, 274

Antihypertensive regimes, realistic evaluation. January, 7

*Aorta, abdominal spontaneous rupture. April, 231

Aortic aneurysms abdominal, ultrasonic measu rements. December, 737 741

coagulopathy associated with. November, 668

*Aortic stenosis, valvar, with unusual features. June, 326

*Apoplexy, pituitary, clinical features and management. February, 82

*Appendicitis, acute, associated with non-obstructive carcinoma of caecum. April, 234

Arrhythmias, ventricular, in acute myocardial infarction, prognostic importance. February, 69

*Ascites, myxoedema, complicating ischaemic heart disease. June, 343

*Aspergillosis, disseminated, and miliary tuberculosis. November, 709

Asthma, childhood, comparison of betamethasone valerate and sodium cromoglycate treatment. June, 315

Atenolol in hypertension, comparison of once and twice daily. November, 679

Atrium, left, enlargement, comparison of electro- and echocardiographic measurements. July, 356

Auscultation of elderly heart, pathological validation. February, 66

Autoantibodies, practolol-induced, relation to oculocutaneous complications. February, 75

*Auto-immune thyroid disease, chronic liver disease and eosinophilia in ulcerative colitis. February, 105

Azathioprine therapy associated with acute leukaemia. March, 173: correspondence, July, 430.

*Bacillus cereus bacteraemia in patient receiving 5-fluorouracil. July, 397

Bacteriuria, screening, Microstix and dipslides. May, 248

*Barbiturates neonatal withdrawal syndrome. March, 157 and serum calcium in the elderly. April, 212

Basal ganglia, biochemistry, and Parkinson's disease. December, 719

Becker's X-linked muscular dystrophy, congestive cardiomyopathy in. January, 12

*Beckwith's syndrome, management of prolonged hypoglycaemia. March, 159

*Behçet's syndrome with perforations of the colon. February, 108

Betamethasone valerate compared with sodium cromoglycate in asthmatic children. June, 315

* Biliary tree, granular cell myoblastoma. September, 574

* Bladder carcinoma, associated with inappropriate antidiuretic hormone secretion. May, 274

* leiomyosarcoma, associated with leukaemoid reaction. December, 766 